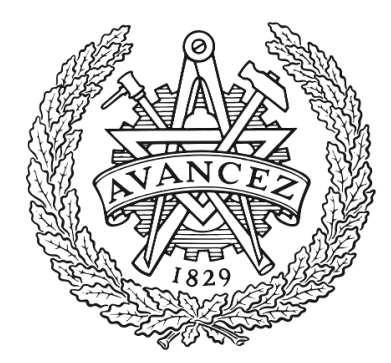

\title{
CHALMERS
}

UNIVERSITY OF TECHNOLOGY

\section{Methane oxidation over Pt/Al2O3 and Pd/Al2O3 catalysts under transient conditions}

Downloaded from: https://research.chalmers.se, 2023-04-26 10:49 UTC

Citation for the original published paper (version of record):

Carlsson, P., Fridell, E., Skoglundh, M. (2007). Methane oxidation over Pt/Al2O3 and Pd/Al2O3 catalysts under transient conditions. Catalysis Letters, 115(1-2): 1-7. http://dx.doi.org/10.1007/s10562-007-9057-1

N.B. When citing this work, cite the original published paper. 


\title{
Methane oxidation over $\mathrm{Pt} / \mathrm{Al}_{2} \mathrm{O}_{3}$ and $\mathrm{Pd} / \mathrm{Al}_{2} \mathrm{O}_{3}$ catalysts under transient
}

\author{
conditions \\ Per-Anders Carlsson ${ }^{\mathrm{a}, ~}{ }^{*}$, Erik Fridell ${ }^{\mathrm{b}}$ and Magnus Skoglundh ${ }^{\mathrm{a}}$ \\ ${ }^{\mathrm{a} C}$ Competence Centre for Catalysis, \\ Chalmers University of Technology, \\ SE-412 96, Göteborg \\ ${ }^{\mathrm{b}}$ IVL Swedish Environmental Research Institute \\ PO Box 5302, \\ SE-400 14 Göteborg
}

\begin{abstract}
We communicate experimental results for the oxidation of methane by oxygen over alumina supported Pd and Pt monolith catalysts under transient conditions. Temperature programmed reaction (TPReaction) and reactant pulse-response (PR) experiments have been performed, using a continuous gas-flow reactor equipped with a downstream mass spectrometer for gas phase analysis. Special attention was paid to the influence of gas composition changes, i.e. $\mathrm{O}_{2}$ and $\mathrm{H}_{2}$ pulsing, respectively, on the methane conversion. For $\mathrm{Pt} / \mathrm{Al}_{2} \mathrm{O}_{3}$ oxygen pulsing can significantly increase the methane conversion which can be even further improved by pulsing hydrogen instead. Such transient effects are not observed for the $\mathrm{Pd} / \mathrm{Al}_{2} \mathrm{O}_{3}$ catalyst for which instead constantly lean conditions is beneficial. Our results suggest that under lean conditions
\end{abstract}


Pd and Pt crystallites may undergo bulk- and partial (surface oxide formation) oxidation, respectively, which for Pd results in more active surfaces, while for Pt the activity is reduced. The latter seems to connect to a lowering of the ability to dissociate methane.

Key words: Catalytic methane oxidation; Pulse-response experiments; Periodic operation; Platinum oxide; Palladium oxide; $\mathrm{Pt} / \mathrm{Al}_{2} \mathrm{O}_{3} ; \mathrm{Pd} / \mathrm{Al}_{2} \mathrm{O}_{3}$

\section{Introduction}

The huge world reserve of natural gas, which essentially is methane $\left(\mathrm{CH}_{4}\right)$, appears as an attractive source of energy for heat and power production, and propulsion. The low amounts of sulphur- and nitrogen containing constituents in natural gas are beneficial and give low emission levels of sulphur and nitrogen oxides $\left(\mathrm{SO}_{\mathrm{x}}\right.$ and $\left.\mathrm{NO}_{\mathrm{x}}\right)$ during combustion. For efficient and environmentally sustainable conversion of methane, catalytic combustion offers an attractive alternative to conventional combustion, since the energy is released at moderate temperatures and the emission levels of carbon monoxide and nitrogen oxides are relatively low. Since methane is a greenhouse gas, such processes demand controlled methane handling with low methane slip. Moreover, the interest in natural gas fuelled vehicles (NGVs) to solve transportation issues in cities is growing since, compared to diesel engines, NGV engines produce lower amounts of $\mathrm{NO}_{\mathrm{x}}$ and particulates. Natural gas engines can operate under lean conditions keeping the fuel consumption low compared to ordinary (otto) engines running close to stoichiometric conditions. However, the methane conversion is not complete in the combustion chambers (cylinders) and thus catalytic exhaust aftertreatment of methane is an important step in such applications. 
Methane is generally considered as the most difficult hydrocarbon to oxidise where the rate limiting step is the abstraction of the first hydrogen atom $[1,2]$. The most active catalysts for oxidation of saturated hydrocarbons, including $\mathrm{CH}_{4}$, are the noble metals platinum and palladium where the latter in most cases is considered superior. Often the light-off temperature $\left(\mathrm{T}_{50}\right)$, i.e., the inlet gas temperature at which $50 \%$ conversion is achieved [3], for oxidation of methane by oxygen over typical $\mathrm{Pt} / \mathrm{Al}_{2} \mathrm{O}_{3}$ catalysts is in the range $625-725 \mathrm{~K}$ [4, 5]. The corresponding temperatures for alumina supported $\mathrm{Pd}$ is about $50-75 \mathrm{~K}$ lower [6]. Although oxidation of methane has been studied for decades, the underlying mechanism, and thus the active state of the catalyst, is still under debate. For Pt catalysts neither a completely reduced nor a fully oxidised surface is optimal for methane oxidation. Instead, partially oxidised metal surfaces where the concentrations of adsorbed oxygen and methane are well balanced seem to be the most active [7]. Such surfaces can, probably, more effectively polarise the methane molecule and thereby also more efficiently break the $\mathrm{C}-\mathrm{H}$ bond $[1,2]$. In the case of palladium based catalysts, i.e. $\mathrm{Pd} / \mathrm{Al}_{2} \mathrm{O}_{3}$, the oxidised form, $\mathrm{PdO}$, is the most active state for methane oxidation [7]. Comparison between $\mathrm{Pt} / \mathrm{Al}_{2} \mathrm{O}_{3}$ and $\mathrm{Pd} / \mathrm{Al}_{2} \mathrm{O}_{3}$ catalysts show that $\mathrm{Pd}$ is the most appropriate choice for lean reaction conditions and at low conversions under stoichiometric or rich conditions whereas $\mathrm{Pt} / \mathrm{Al}_{2} \mathrm{O}_{3}$ is more efficient at higher conversions with stoichiometric or rich conditions [7].

Previously, Pt-based catalysts have been used to study transient effects in the oxidation of CO $[8,9]$ and $\mathrm{C}_{3} \mathrm{H}_{6}[8]$, so-called self-poisoned systems, and $\mathrm{C}_{3} \mathrm{H}_{8}[10]$. For the latter, interesting results indicating i) the existence of an optimum catalyst state for high propane conversion and ii) that this optimum could be approached by periodic operation of the gas composition, i.e., introducing rich periods to otherwise lean conditions, were shown. It is valuable to complement this work with studies of methane oxidation at transient conditions, since, for 
example, methane is chemically very different compared to higher alkanes. It is also interesting to broaden such studies by including also other catalysts.

The aim with this letter is to study transient effects in the methane oxidation over $\mathrm{Pd} / \mathrm{Al}_{2} \mathrm{O}_{3}$ and $\mathrm{Pt} / \mathrm{Al}_{2} \mathrm{O}_{3}$ model catalysts. Special attention was paid to i) the influence of gas composition changes (periodic operation) on the methane conversion and the state of the catalysts, and ii) possible benefits of using periodic operation as a means for high overall $\mathrm{CH}_{4}$ conversion.

\section{Experimental section}

\section{Catalyst preparation and characterisation}

Monolith samples ( $\mathrm{L}=15 \mathrm{~mm}, \varnothing=12 \mathrm{~mm}, 69$ channels) were cut out from a commercial honeycomb structure of cordierite with 400 cpsi. The samples were coated with $200 \mathrm{mg} \gamma$ alumina by repeating the cycle; first immersing the sample into a dilute ammonia solution $(\mathrm{pH}=11)$ and then into an aqueous $\gamma$-alumina slurry consisting of $13 \mathrm{wt} \% \gamma$-alumina, $3 \mathrm{wt} \%$ bohemite and $1 \mathrm{wt} \%$ nitric acid (excess slurry was gently removed by blowing air through the channels) followed by gentle drying at $365 \mathrm{~K}$ in air and calcination at $825 \mathrm{~K}$ for $2 \mathrm{~min}$, also in air. The samples were then calcined at $850 \mathrm{~K}$ in stationary air for $90 \mathrm{~min}$.

Catalysts with $10 \mathrm{mg}$ of either Pt or Pd were prepared by impregnating the samples with an aqueous solution of platinum(II)nitrate and palladium(II)nitrate, respectively, as the precursor for the active component. The samples were dried and calcined in stationary air at $365 \mathrm{~K}$ for $5 \mathrm{~h}$ and $850 \mathrm{~K}$ for $90 \mathrm{~min}$, respectively, and reduced in $4 \% \mathrm{H}_{2}$ at $725 \mathrm{~K}$ for $60 \mathrm{~min}$ followed by exposure to a net-oxidising mixture consisting of 1.0 vol.- $\% \mathrm{CO}, 0.15$ vol.- $\% \mathrm{C}_{3} \mathrm{H}_{6}$ and 1.4 
vol.- $\% \mathrm{O}_{2}\left(\mathrm{~N}_{2}\right.$ as balance $)$ at $825 \mathrm{~K}$ for $90 \mathrm{~min}$ at a total flow rate of $3000 \mathrm{ml} / \mathrm{min}$. In the following vol.- $\%$ will be noted by $\%$.

\section{Flow-reactor measurements}

The methane oxidation experiments were performed in a continuous gas-flow reactor consisting of a quartz tube $(\mathrm{L}=400 \mathrm{~mm}, \varnothing=15 \mathrm{~mm})$ wherein the sample was positioned. Heating of inlet gas and the sample occurred via resistive heating of a metal coil surrounding the tube. Both the inlet gas and the catalyst temperature were measured by separate thermocouples (type K). Gases were introduced via individual mass flow controllers. The product stream was continuously analysed with a mass spectrometer (Balzers Quadstar 422) following the m/e ratios $2\left(\mathrm{H}_{2}\right), 15\left(\mathrm{CH}_{4}\right), 18\left(\mathrm{H}_{2} \mathrm{O}\right), 28(\mathrm{CO}), 32\left(\mathrm{O}_{2}\right) 40(\mathrm{Ar})$ and $44\left(\mathrm{CO}_{2}\right)$. The $\mathrm{H}_{2} \mathrm{O}$ signal, however, is not shown due to low accuracy connected to lag time with our reactor set-up. Different temperature programmed reaction (TPReaction) and pulse-response (PR) experiments were performed as summarised in Table 1. In all experiments a total gas flow of $200 \mathrm{ml}(\mathrm{NTP}) / \mathrm{min}$, corresponding to a space velocity of $7000 \mathrm{~h}^{-1}$ was used (Ar as balance).

\section{Results}

Figure 1 and 2 show the TPReaction results for the $\mathrm{Pd} / \mathrm{Al}_{2} \mathrm{O}_{3}$ and $\mathrm{Pt} / \mathrm{Al}_{2} \mathrm{O}_{3}$ catalysts, respectively, at both net-oxidising (lean) and net-reducing (rich) conditions. For the Pd sample, the $\mathrm{CH}_{4}$ concentration starts to decrease slowly at about $500 \mathrm{~K}$ for both lean and rich conditions and at $560 \mathrm{~K}$ a more rapid decrease is seen. A corresponding increase and decrease in the $\mathrm{CO}_{2}$ and oxygen concentrations, respectively, can also be observed. For lean conditions, the $\mathrm{T}_{50}$ is about $620 \mathrm{~K}$, which is about $25 \mathrm{~K}$ lower than the corresponding temperature at rich 
conditions, and complete conversion of $\mathrm{CH}_{4}$ into $\mathrm{CO}_{2}$ is achieved at around $700 \mathrm{~K}$. An interesting observation is the minimum in the $\mathrm{O}_{2}$ response at this temperature. Although during conditions with oxygen deficiency all oxygen is consumed at around $670 \mathrm{~K}$, complete $\mathrm{CH}_{4}$ conversion is nevertheless observed at about $700 \mathrm{~K}$ due to changing reaction selectivity, i.e., formation of $\mathrm{H}_{2}$ in this case. Also for the $\mathrm{Pt} / \mathrm{Al}_{2} \mathrm{O}_{3}$ catalyst, the $\mathrm{CH}_{4}$ conversion starts at about the same temperature for lean and rich conditions, however, contrary to the results for the $\mathrm{Pd}$ catalyst, the $\mathrm{T}_{50}$ is lower for rich compared to lean conditions, about $690 \mathrm{~K}$ compared to $705 \mathrm{~K}$. For rich conditions, complete $\mathrm{CH}_{4}$ conversion is reached at lower temperatures compared to lean conditions. A change in reaction selectivity towards $\mathrm{H}_{2}$ formation as previously observed for the Pd sample can be seen also in this case.

The results from the oxygen $\mathrm{PR}$ experiments for the $\mathrm{Pd} / \mathrm{Al}_{2} \mathrm{O}_{3}$ and $\mathrm{Pt} / \mathrm{Al}_{2} \mathrm{O}_{3}$ catalyst, respectively, are shown in Figure 3 and 4. The outlet concentrations of $\mathrm{O}_{2}$ and $\mathrm{H}_{2}$ (top panel), $\mathrm{CH}_{4}$ and $\mathrm{CO}$ (middle panel), and $\mathrm{CO}_{2}$ with the addition of the carbon balance (bottom panel) are shown as a function of time for periods with repeatable responses.

For the $\mathrm{Pd} / \mathrm{Al}_{2} \mathrm{O}_{3}$ sample (see Figure 3), during the initial phase of the introduction of a 1250 ppm oxygen pulse at $\mathrm{t}=26 \mathrm{~min}$, a temporary minimum in the $\mathrm{CH}_{4}$ concentration and a corresponding temporary maximum in the $\mathrm{CO}_{2}$ concentration are clearly visible. The responses in $\mathrm{CH}_{4}$ and $\mathrm{CO}_{2}$ concentrations are seen slightly before any observable change in oxygen concentration. Upon further oxygen exposure then, $\mathrm{t}=26-31 \mathrm{~min}$, both the $\mathrm{CH}_{4}$ and $\mathrm{O}_{2}$ concentration decrease continuously with a corresponding increase of $\mathrm{CO}_{2}$ concentration. The carbon balance is steady at $500 \mathrm{ppm} \mathrm{C}$ during this period. At $\mathrm{t}=31 \mathrm{~min}$, the oxygen feed is switched off and the oxygen concentration drops quickly to zero. The $\mathrm{CO}_{2}$ concentration passes a small concentration maximum, drops then for about 1 min and finally decreases more 
slowly for the next 4 min. Both the $\mathrm{CH}_{4}$ concentration and the carbon balance pass through individual minima. The $\mathrm{CH}_{4}$ concentration increases then slowly towards $500 \mathrm{ppm}$, however, reaches only $450 \mathrm{ppm}$ since a new oxygen pulse is introduced at $\mathrm{t}=36 \mathrm{~min}$. During the oxygen-free period, $\mathrm{H}_{2}$ and minor amounts of $\mathrm{CO}$ are formed.

The introduction of an oxygen pulse to the $\mathrm{Pt} / \mathrm{Al}_{2} \mathrm{O}_{3}$ sample (Figure 4) at $\mathrm{t}=36 \mathrm{~min}$, results in a huge and relatively broad minimum in $\mathrm{CH}_{4}$ concentration, reaching an almost complete $\mathrm{CH}_{4}$ conversion for a short period. A corresponding maximum in the $\mathrm{CO}_{2}$ concentration and a somewhat lower maximum in the carbon balance also occur. These responses are observed before any major change can be seen in the $\mathrm{O}_{2}$ concentration. However, the transient responses are more pronounced and the observed maximum in methane conversion during this switch is considerably higher for the $\mathrm{Pt} / \mathrm{Al}_{2} \mathrm{O}_{3}$ sample. Contrary to the previous results for $\mathrm{Pd} / \mathrm{Al}_{2} \mathrm{O}_{3}$, a stationary $\mathrm{CH}_{4}$ concentration is reached during continuous oxygen exposure. Considering the $\mathrm{O}_{2}$ switch-off at $\mathrm{t}=41 \mathrm{~min}$, a minimum in $\mathrm{CH}_{4}$ concentration is passed again where after the $\mathrm{CH}_{4}$ concentration approaches $300 \mathrm{ppm}$. The carbon balance passes a minimum. During this switch a considerable amount of $\mathrm{H}_{2}$ is formed while $\mathrm{CO}$ starts to be produced. While the $\mathrm{H}_{2}$ concentration decreases from about 1100 to $500 \mathrm{ppm}$, the $\mathrm{CO}$ concentration increases monotonically towards $100 \mathrm{ppm}$

The results from the PR experiments where $\mathrm{H}_{2}$ pulses were introduced to a slightly oxidising $\mathrm{CH}_{4} / \mathrm{O}_{2} / \mathrm{Ar}$ mixture for the $\mathrm{Pd} / \mathrm{Al}_{2} \mathrm{O}_{3}$ and $\mathrm{Pt} / \mathrm{Al}_{2} \mathrm{O}_{3}$ catalysts are shown in Figure 5 and 6 , respectively. For the $\mathrm{Pd} / \mathrm{Al}_{2} \mathrm{O}_{3}$ sample, the results are similar to the oxygen PR experiments described above. During the introduction of a $0.5 \% \mathrm{H}_{2}$ pulse at $\mathrm{t}=37$ min results in a temporary minimum both in the $\mathrm{CH}_{4}$ concentration and in the carbon balance while the $\mathrm{CO}_{2}$ concentration drops to about zero. However, for the Pt sample a broad and deep minimum in 
the $\mathrm{CH}_{4}$ concentration is seen when the hydrogen is switched off at $\mathrm{t}=36 \mathrm{~min}$. The $\mathrm{CH}_{4}$ concentration minimum corresponds with a broad and high maximum in $\mathrm{CO}_{2}$ production.

\section{Discussion}

Palladium and platinum are precious metals with very different ability to incorporate oxygen into the atomic metal structure, i.e., form oxides [11]. Depending on the reaction conditions, $\mathrm{Pd}$ is known to form $\mathrm{PdO}$ in supported catalysts during reaction conditions [12]. The oxidation of a Pd crystallite is not restricted to just the surface region of the metal particles but can reach several atomic layers [13], thus relatively large amounts of oxygen can be incorporated into the Pd structure. For Pt, no evidence for such bulk oxidation has been found, however, neither the oxide stoichiometry nor the stability of the oxides is well known. The oxide phase of Pt is usually referred to as "surface oxide" or "subsurface oxide", terms which are often used interchangeably. In the results presented here it is clear that the influence of the gas composition on the activity for methane oxidation as well as the transient response to gas composition changes are considerable different for $\mathrm{Pd}$ and $\mathrm{Pt}$ based catalysts respectively. Since no spectroscopic methods were used in the present study, we can not unambiguously discuss the catalyst state. However, guided by the cited references and previous results for $\mathrm{Pt} / \mathrm{Al}_{2} \mathrm{O}_{3}$ [14], showing that $\mathrm{Pt}$ can be partially oxidised during $\mathrm{CO}$ oxidation at oxygen excess, we may draw a number of conclusions. In the following, we thus focus on the influence of the gas composition on methane conversion and state of the catalysts and how these are linked together. We follow up with commenting on potential benefits using periodic operation for high overall methane conversion. 
Comparing Figure 1 and 2, it is clear that the oxygen level has significantly different influence on the methane conversion for the Pd and Pt catalysts, respectively. For the Pd catalyst, the oxidation of methane is governed by oxygen excess, the $\mathrm{T}_{50}$ is lower for lean compared to rich conditions, whilst for Pt, excess oxygen clearly suppress the reaction as reflected by the higher $\mathrm{T}_{50}$ in this case. Likely, see discussion above, both samples form oxides during oxygen excess conditions. The drop in the oxygen concentration for the Pd sample after light-off and the transition via a concentration minimum strongly suggests that the $\mathrm{Pd}$ sample stores a considerable amount of oxygen, i.e., bulk oxidation of the $\mathrm{Pd}$ crystallites, which governs the oxidation of methane. The corresponding results for the $\mathrm{Pt}$ catalyst show only a moderate decrease in $\mathrm{O}_{2}$ concentration indicating no such bulk oxidation. Instead, the Pt crystallites may only be partially oxidised (surface oxide formation). However, the formation of surface oxide significantly lowers the activity of the catalyst, probably by decreasing the methane adsorption rate, i.e., reducing the ability to dissociate $\mathrm{CH}_{4}$. This is motivated by comparing the results for rich and lean conditions (Figure 2) where during rich conditions complete $\mathrm{CH}_{4}$ conversion into $\mathrm{CO}_{2}, \mathrm{CO}$ and $\mathrm{H}_{2}$ is observed at the higher temperatures while under lean conditions the $\mathrm{CH}_{4}$ conversion is incomplete with no formation of $\mathrm{CO}$ or $\mathrm{H}_{2}$. Contrary, no such behaviour is observed for the Pd catalyst (Figure 1).

The different roles of oxide formation are further emphasised in the PR experiments presented in Figure 3 and 4, respectively. For Pd, the introduction of an oxygen pulse initially results in a temporary over-production of $\mathrm{CO}_{2}$. This is partly due to a transition from a mainly $\mathrm{CH}_{4}$ covered to an almost $\mathrm{O}$ covered surface, as evidenced by the positive peak in the carbon balance, and partly due to the passage of a surface composition, i.e. certain $\mathrm{CH}_{4}$ and $\mathrm{O}$ coverages, which is beneficial for the activity as indicated by the temporary minimum in the $\mathrm{CH}_{4}$ concentration. After passing this transient regime with high activity, the system reaches a 
state with almost no conversion of methane $(\mathrm{t}=27.6 \mathrm{~min})$. We believe that this state corresponds to a Pd surface being either covered with a monolayer of $\mathrm{O}$ atoms or partially oxidised. Upon further oxygen exposure the catalyst regains activity, increasing methane conversion, which probably correlates to bulk oxidation of the Pd particles becoming more active. From our data, the construction of an oxygen balance is scarce due to experimental difficulties following the water signals. However, from Figure 3 one may observe that the oxygen concentration decreases slightly more than expected from the corresponding $\mathrm{CO}_{2}$ production supporting the idea of a Pd bulk oxidation process. The temporary minimum in the $\mathrm{CH}_{4}$ response occurring for the $\mathrm{O}_{2}$ switch-off at $\mathrm{t}=31 \mathrm{~min}$ is mostly due to re-adsorption of methane as clearly supported by the simultaneous minimum in the carbon balance. While metal oxidation seems to be beneficial for Pd the contrary is, again, true for Pt. In Figure 4, the introduction of oxygen at $\mathrm{t}=36$ min results in an initial huge temporary minimum in $\mathrm{CH}_{4}$ concentration as the catalyst surface composition switches from being mainly $\mathrm{CH}_{4}$ covered to almost $\mathrm{O}$ covered (maximum in carbon balance) similar to the Pd case. However, as a function of time on stream the methane conversion quickly decays towards a stationary state with a relatively low $\mathrm{CH}_{4}$ conversion, i.e., the formation of a surface oxide layer reduces the activity for methane oxidation considerably. The negative influence of oxygen excess is further supported by the temporary high activity (maximum in $\mathrm{CO}_{2}$ concentration) as the oxygen is switched off at $\mathrm{t}=41 \mathrm{~min}$. The simultaneous passage through a concentration minimum for $\mathrm{CH}_{4}$ is mainly due to a temporary high adsorption of $\mathrm{CH}_{4}$ (minimum in carbon balance)

To lower the effect of accumulated methane on the metal surface and thereby more clearly study the effect of oxide formation on the methane oxidation one may use constant concentration levels of methane and oxygen and dose hydrogen (instead of oxygen) as shown 
in Figure 5 and 6 for the Pd and Pt sample, respectively. For the Pd sample it is again clear that a certain surface composition on a metal like Pd is highly active. The hydrogen shut off at $\mathrm{t}=31$ min results in a temporary minimum in $\mathrm{CH}_{4}$ concentration and a corresponding temporary maximum in $\mathrm{CO}_{2}$ concentration. The maximum in the carbon balance reveals a certain change in surface coverage from partly $\mathrm{CH}_{4}$ to more or less $\mathrm{O}$ covered, however, contrary to the analogous oxygen pulsing experiment (Figure 3) the present maximum reaches a top level of 625 vol.-ppm instead of 800 vol.-ppm indicating less amounts of adsorbed $\mathrm{CH}_{4}$ in this case and thus the high activity is mainly due to a beneficial surface composition. During further oxygen exposure, the methane conversion increases continuously analogous to previous results. However, the most interesting response to hydrogen pulsing is seen for the $\mathrm{Pt}$ sample. When hydrogen is switched off, a huge and relatively broad minimum in $\mathrm{CH}_{4}$ concentration is seen together with the corresponding $\mathrm{CO}_{2}$ production. The carbon balance is more or less constant for this period and thus the high $\mathrm{CO}_{2}$ production is solely due to high activity. The enhanced methane oxidation kinetics is probably a result of hydrogen acting as a clean-up molecule preventing the surface from being deactivated by surface oxide formation.

\section{Conclusions}

Our results show that for methane oxidation with oxygen under lean conditions $\mathrm{Pd} / \mathrm{Al}_{2} \mathrm{O}_{3}$ is superior to $\mathrm{Pt} / \mathrm{Al}_{2} \mathrm{O}_{3}$. Under these conditions both metals undergoes oxidation, however, the degree of oxidation and the impact on the methane oxidation differs considerably between the two metals. While the Pd crystallites may form bulk oxides resulting in highly active surfaces the Pt crystallites seem to be only partially oxidised (surface oxide formation) resulting in surfaces with low catalytic activity. The latter seems to connect to a lowering of the ability to dissociate methane. The results also suggest that for both catalysts optimal surface 
compositions, i.e., $\mathrm{CH}_{4}$ and $\mathrm{O}$ coverages, may exist for which the methane oxidation activity is high.

During periodic operation (oxygen pulsing) of the $\mathrm{Pt} / \mathrm{Al}_{2} \mathrm{O}_{3}$ catalyst an increased activity was observed while switching from rich to lean conditions as compared to stationary conditions analogous to previous results for oxidation of $\mathrm{CO}[8,9], \mathrm{C}_{3} \mathrm{H}_{6}[8]$ and $\mathrm{C}_{3} \mathrm{H}_{8}$ [10]. The activity improvement was even more pronounced when periodic operation with hydrogen pulses, i.e., switching between hydrogen and $\mathrm{CH}_{4}$ oxidation, was used.

\section{References}

[1] R. Burch and M.J. Hayes, J. Mol. Catal. A: Chem. 100 (1997) 13.

[2] R. Burch, D.J. Crittle and M.J. Hayes, Catal. Today 47 (1999) 229.

[3] J.T. Kummer, Prog. Energy Combust. Sci. 6 (1980) 177.

[4] R. Burch and P.K. Loader, Appl. Catal. B: Environ. 5 (1994) 149.

[5] T.P. Garetto and C.R. Apesteguia, Catal. Today 62 (2000) 189.

[6] P. Gélin and M. Primet, Appl. Catal. B. 39 (2002) 1.

[7] R. Burch, P.K. Loader and F.J. Urbano, Catal. Today 27 (1996) 243.

[8] P.-A. Carlsson, P. Thormählen, M. Skoglundh, H. Persson, E. Fridell, E. Jobson, and B. Andersson, Top. Catal. 16/17(1-4) (2001) 343.

[9] P.-A. Carlsson, M. Skoglundh, E. Fridell, E. Jobson and B. Andersson, Catal. Today 73 (2002) 307.

[10] P.-A. Carlsson, S. Mollner, K. Arnby and M. Skoglundh, Chem. Eng. Sci. 59 (2004) 4313.

[11] C. Cullis and B. Willatt, J. Catal. 83 (1983) 267.

[12] O. Demoulin, M. Navez, E. Gaigneaux, P. Ruiz, A.-S. Mamede, P. Granger and E. Payen, Phys. Chem. Chem. Phys. 5 (2003) 4394. 
[13] D. Ciuparu, M. Lyubovsky, E. Altman, L. Pfefferle and A. Datye, Catal. Rev. 44 (2002) 593.

[14] P.-A. Carlsson, L. Österlund, P. Thormählen, A. Palmqvist, E. Fridell, J. Jansson and M. Skoglundh, J. Catal. 226 (2004) 422. 
Table 1. Summary of the experimental conditions for the flow-reactor measurements.

\begin{tabular}{|c|c|c|c|c|c|}
\hline \multirow{2}{*}{$\begin{array}{c}\text { Type of } \\
\text { experiment }\end{array}$} & Sample & \multirow{2}{*}{$\begin{array}{c}\text { Temperature } \\
{[\mathbf{K}]}\end{array}$} & $\begin{array}{c}\text { G } \\
\text { [ppm] }\end{array}$ & $\begin{array}{c}\mathbf{O}_{\mathbf{2}} \text { conc. [ppm]/ } \\
\text { (duration [min]) }\end{array}$ & $\begin{array}{c}\mathbf{H}_{\mathbf{2}} \text { conc. [ppm]/ } \\
\text { (duration [min]) }\end{array}$ \\
\hline $\begin{array}{c}\text { TPReaction } \\
\text { (rich) }\end{array}$ & $\begin{array}{c}\mathrm{Pd} / \mathrm{Al}_{2} \mathrm{O}_{3} \\
\mathrm{Pt} / \mathrm{Al}_{2} \mathrm{O}_{3}\end{array}$ & $\begin{array}{c}303=>773 \\
(20 \mathrm{~K} / \mathrm{min})\end{array}$ & 500 & 750 & -- \\
\hline $\begin{array}{c}\text { TPReaction } \\
\text { (lean) }\end{array}$ & $\begin{array}{c}\mathrm{Pd} / \mathrm{Al}_{2} \mathrm{O}_{3} \\
\mathrm{Pt} / \mathrm{Al}_{2} \mathrm{O}_{3}\end{array}$ & $\begin{array}{c}303=>773 \\
(20 \mathrm{~K} / \mathrm{min})\end{array}$ & 500 & 1250 & -- \\
\hline PR (lean-rich) & $\mathrm{Pd} / \mathrm{Al}_{2} \mathrm{O}_{3}$ & 623 & 500 & $1250(5) / 0(5)$ & -- \\
\hline PR (rich-lean) & $\mathrm{Pd} / \mathrm{Al}_{2} \mathrm{O}_{3}$ & 623 & 500 & 1250 & $5000(5) / 0(5)$ \\
\hline $\mathrm{PR}$ (lean-rich) & $\mathrm{Pt} / \mathrm{Al}_{2} \mathrm{O}_{3}$ & 673 & 500 & $1250(5) / 0(5)$ & -- \\
\hline PR (rich-lean) & $\mathrm{Pt} / \mathrm{Al}_{2} \mathrm{O}_{3}$ & 673 & 500 & 1250 & $5000(5) / 0(5)$ \\
\hline
\end{tabular}

TPReaction=temperature programmed reaction, $\mathrm{PR}=$ pulse-response 


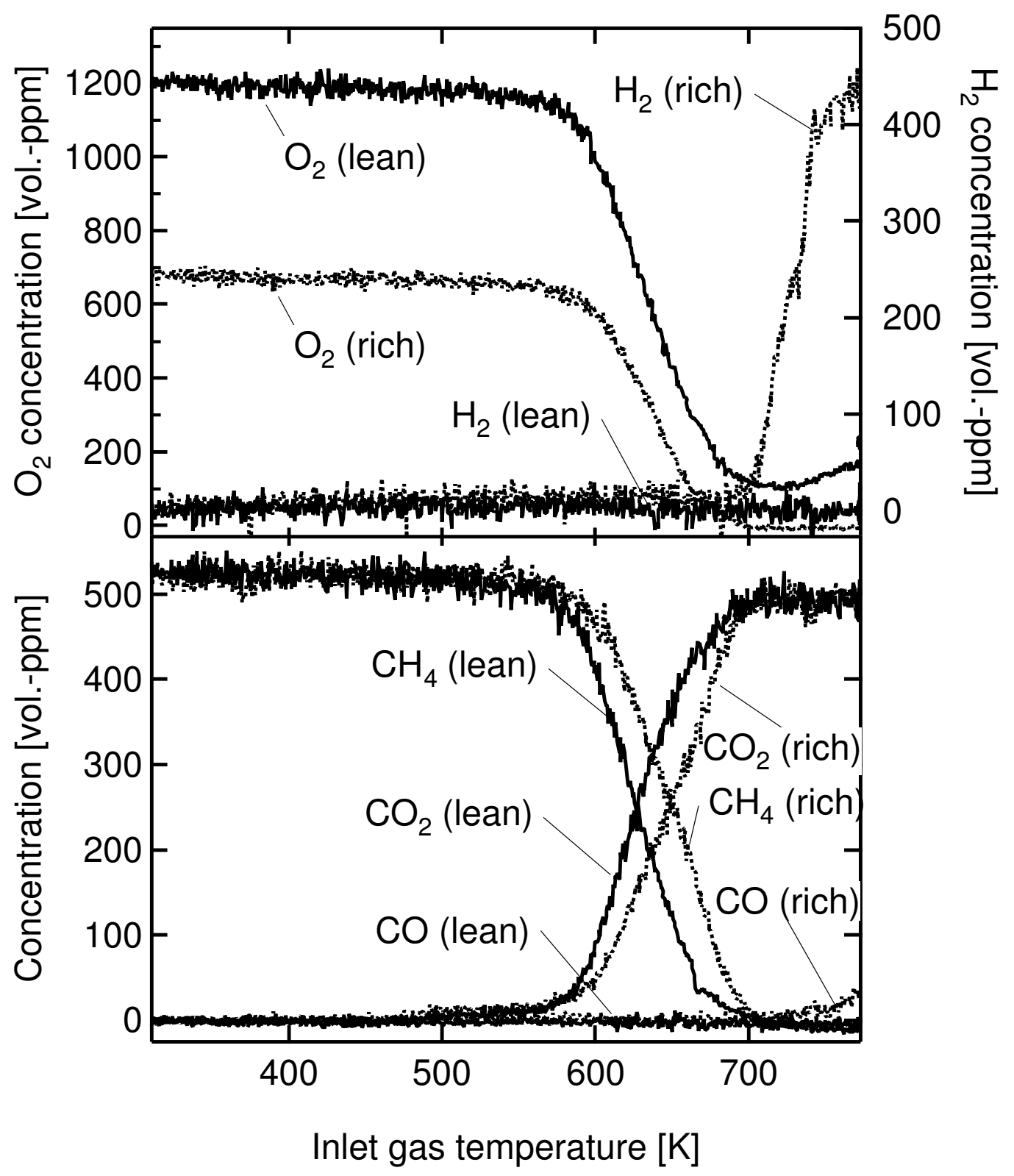

FIG. 1: Temperature programmed oxidation of 500 vol.-ppm $\mathrm{CH}_{4}$ at net-reducing (rich, 750 vol.-ppm $\mathrm{O}_{2}$, dotted line) and netoxidising (lean, 1250 vol.-ppm $\mathrm{O}_{2}$, solid line) conditions, respectively, over a $5 \% \mathrm{Pd} / \mathrm{Al}_{2} \mathrm{O}_{3}$ catalyst. Methane was preadsorbed and the heating ramp was $20 \mathrm{~K} / \mathrm{min}$. 


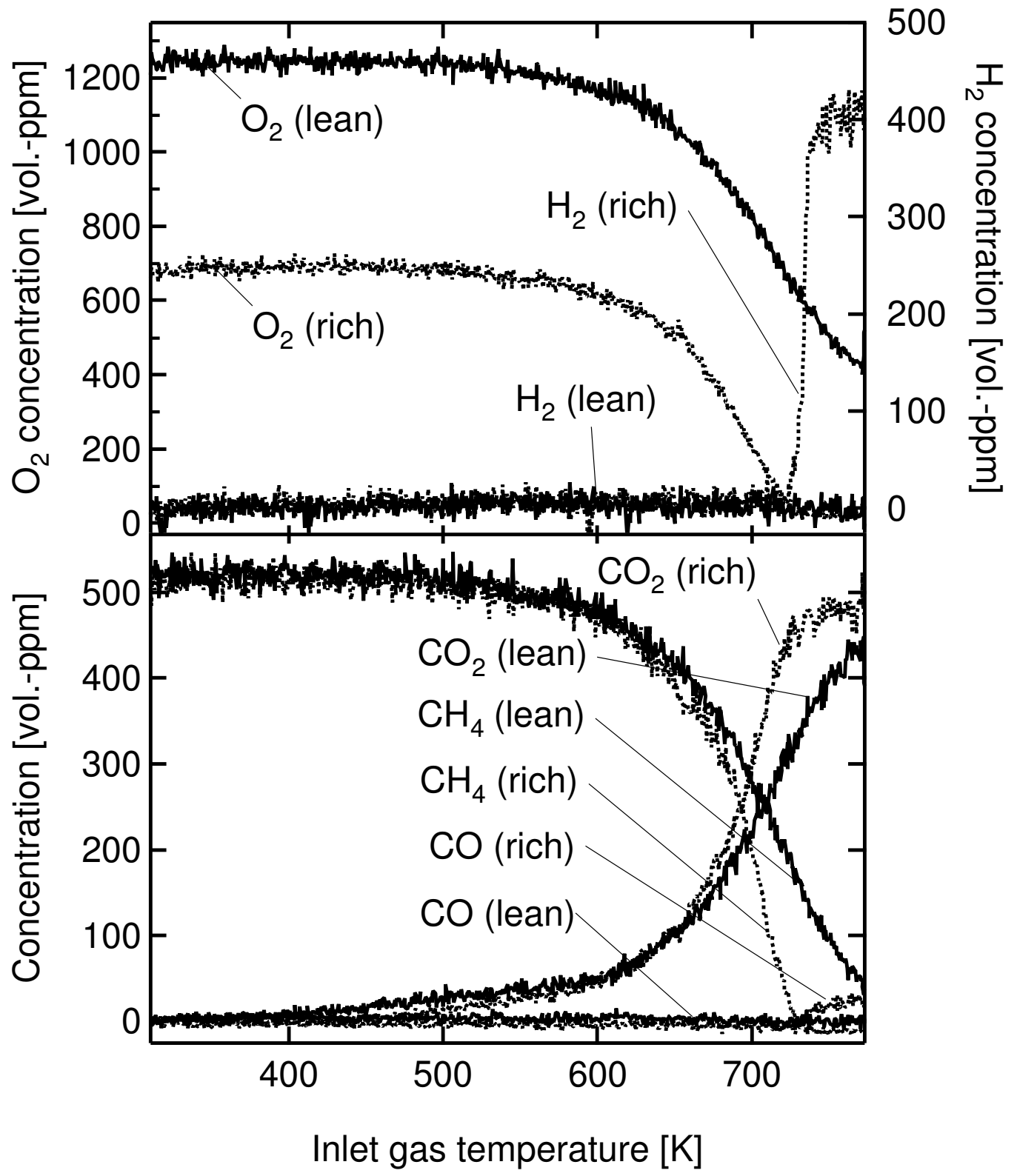

FIG. 2: Temperature programmed oxidation of 500 vol.-ppm $\mathrm{CH}_{4}$ at net-reducing (rich, 750 vol.-ppm $\mathrm{O}_{2}$, dotted line) and netoxidising (lean, 1250 vol.-ppm $\mathrm{O}_{2}$, solid line) conditions, respectively, over a $5 \% \mathrm{Pt} / \mathrm{Al}_{2} \mathrm{O}_{3}$ catalyst. Methane was preadsorbed and the heating ramp was $20 \mathrm{~K} / \mathrm{min}$. 


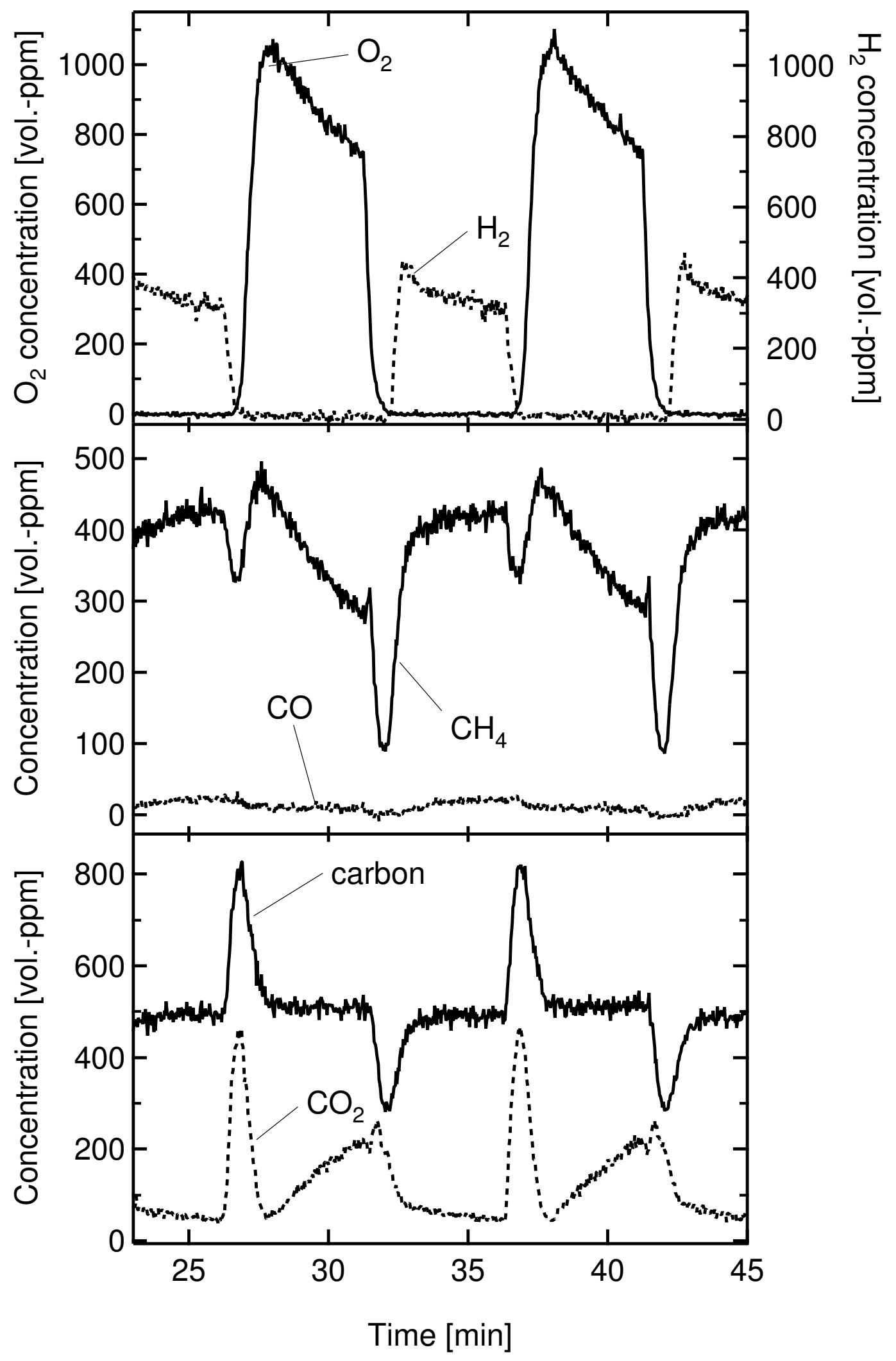

FIG. 3: Oxidation of 500 vol.-ppm $\mathrm{CH}_{4}$ over a $5 \% \mathrm{Pd} / \mathrm{Al}_{2} \mathrm{O}_{3}$ catalyst while periodically varying the oxygen concentration between 0 vol.-ppm for $5 \mathrm{~min}$ and 1250 vol.-ppm also for $5 \mathrm{~min}$ at an inlet gas temperature of $623 \mathrm{~K}$. 


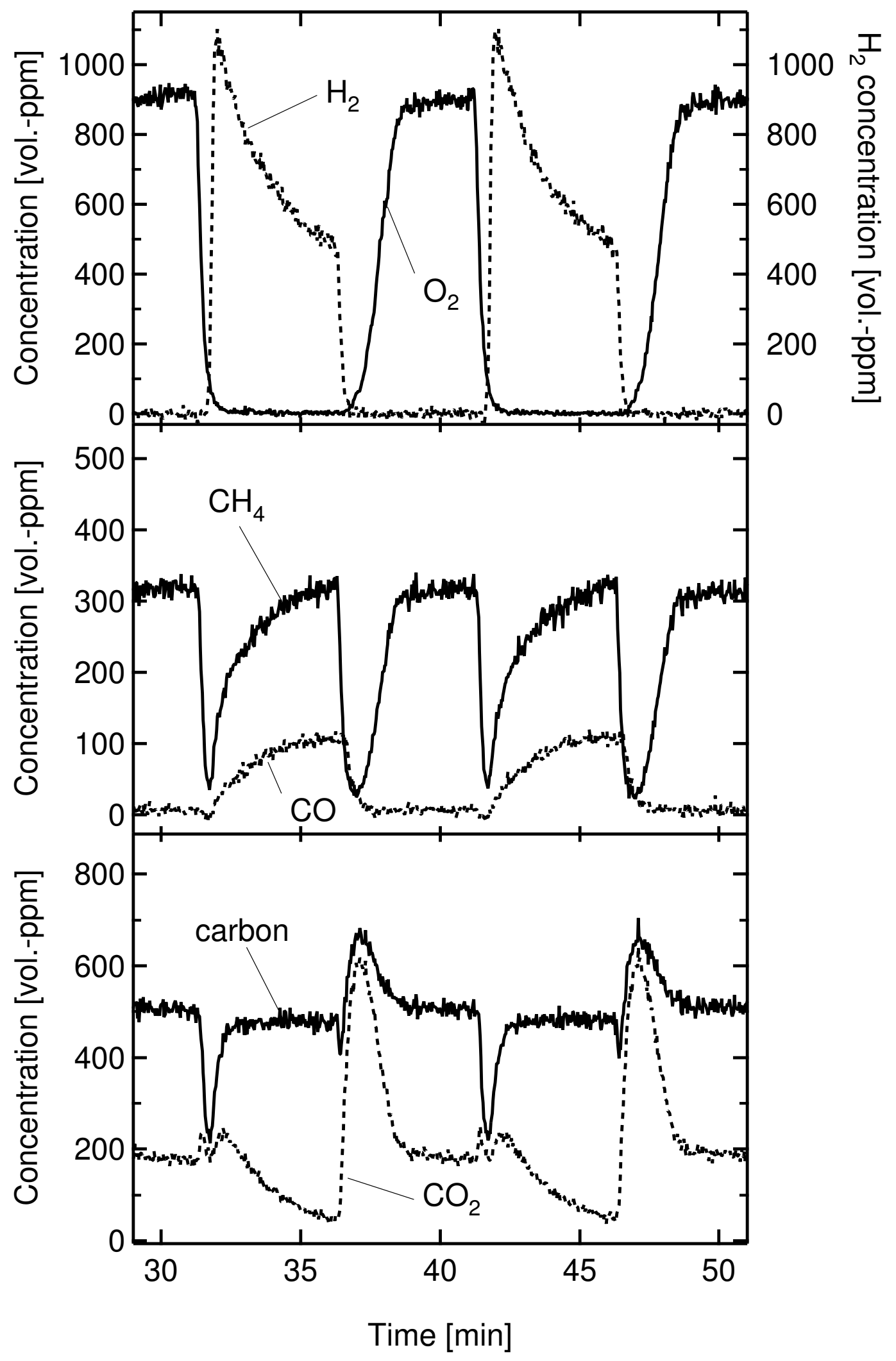

FIG. 4: Oxidation of 500 vol.-ppm $\mathrm{CH}_{4}$ over a $5 \% \mathrm{Pt} / \mathrm{Al}_{2} \mathrm{O}_{3}$ catalyst while periodically varying the oxygen concentration between 0 vol.-ppm for $5 \mathrm{~min}$ and 1250 vol.-ppm also for $5 \mathrm{~min}$ at an inlet gas temperature of $673 \mathrm{~K}$. 


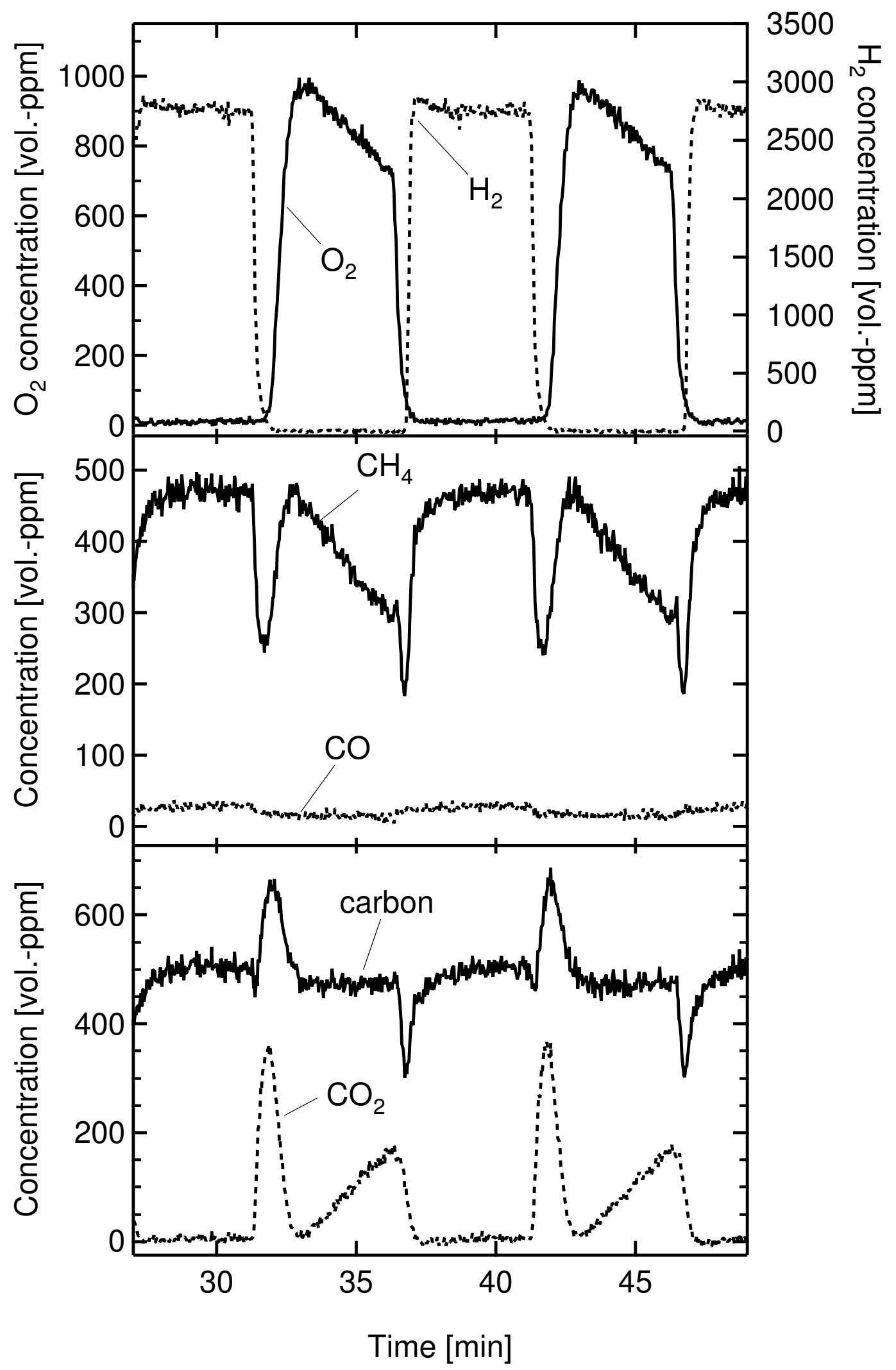

FIG. 5: Oxidation of 500 vol.-ppm $\mathrm{CH}_{4}$ over a $5 \% \mathrm{Pd} / \mathrm{Al}_{2} \mathrm{O}_{3}$ catalyst at net-oxidising conditions $\left(1250\right.$ vol.-ppm $\left.\mathrm{O}_{2}\right)$ while periodically introducing 0.5 vol.- $\% \mathrm{H}_{2}$ for $5 \mathrm{~min}$ at an inlet gas temperature of $623 \mathrm{~K}$. 


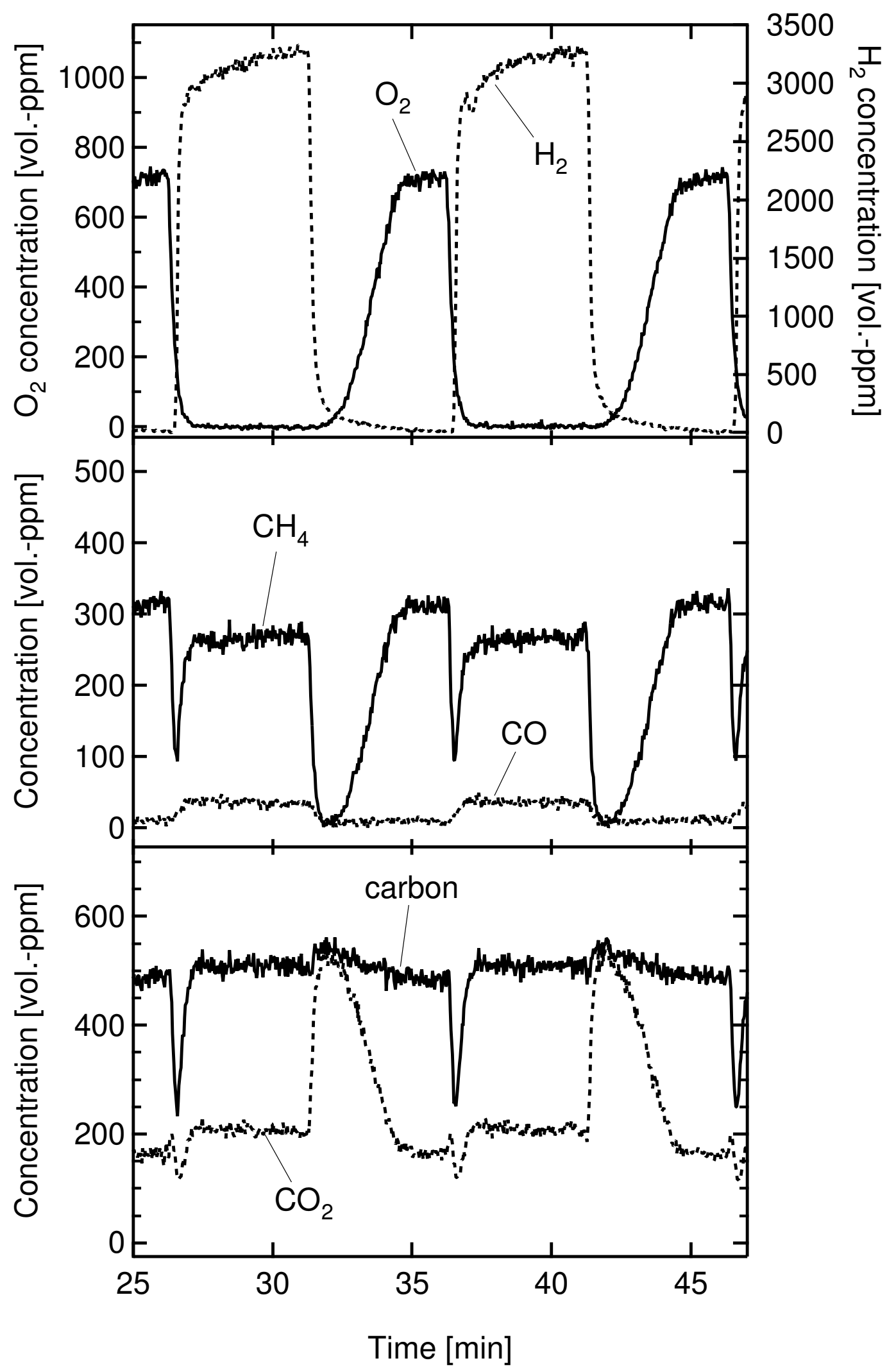

FIG. 6: Oxidation of 500 vol.-ppm $\mathrm{CH}_{4}$ over a $5 \% \mathrm{Pt} / \mathrm{Al}_{2} \mathrm{O}_{3}$ catalyst at net-oxidising conditions $\left(1250\right.$ vol.-ppm $\left.\mathrm{O}_{2}\right)$ while periodically introducing 0.5 vol.- $\% \mathrm{H}_{2}$ for 5 min at an inlet gas temperature of $673 \mathrm{~K}$. 